\title{
HYBRIDIZATION OF NORMAL AND NEOPLASTIC CELLS IN VITRO
}

\author{
By LAWRENCE J. SCALETTA* and BORIS EPHRUSSI $\dagger$
}

Department of Biology, Western Reserve University, Cleveland, Ohio

$\mathrm{T}$

HE occurrence of hybridization of somatic cells in vitro has been established in mixed cultures of several different pairs of permanent mouse cell lines ${ }^{1}$. The purpose of this communication is to describe the hybrids resulting from the mating of cells of a permanent line and freshly explanted diploid cells (the occurrence of these hybrids has been mentioned earlier ${ }^{1}$ ).

The permanent cell line used in our early experiments is Sanford's high cancer line NCTC 2472 of $C 3 H$ origin ${ }^{2}$. The modal chromosome number of the stem line cells $(1 s)$ of 2472 is 49 (variation range: $46-51$ ). Many $2 s$ cells are always present in the population. All cells carry an extra long telocentric chromosome which is an excellent karyological marker; and some of them contain also a long bi-armed chromosome. In later experiments a clone (No. 6) of line NCTC 2472 was used, characterized by a mode of 50 chromosomes (variation range: 48-53). All cells of this clone contain the two aforementioned markers (Fig. 1). This clone contains very few $2 s$ cells.

The normal cells are fibroblast-like cells derived from secondary cultures of skin of new-born $C B A$ mice carrying the well-known T-6 translocation ${ }^{3}$ among its forty telocentric chromosomes (Fig. 2). As can be seen in Fig. 3, the karyotype of the hybrid cells, immediately recognizable by the simultaneous presence of the marker chromosomes of the two parents, is essentially the sum of the two parental karyotypes. The hybrids between cells of clone No. 6 and those of T-6 have a modal chromsome number of 90 (variation: 87-92), as compared with the expected mode of 90 (variation: 88-93).

A low percentage of hybrid mitoses is detected within a few days after the initiation of mixed cultures. However, under the usual culture conditions, the hybrids rapidly disappear from the mixture. During the early stages of a mixed culture, the hybrids can, however, be isolated by cloning. This procedure has permitted the establishment of pure hybrid clones, which appear to be capable of indefinite propagation in vitro. Karyological analysis of these clones has shown that hybrids are formed by mating of diploid $T-6$ cells with both $1 s$ and $2 s$ cells of line NCTC 2472. Inoculation of $10^{6}$ hybrid cells of these two types into $C 3 H$ mice and $F_{1}$ mice from the cross $C 3 H \times C B A$ gave the results presented in Table 1 .

$\begin{array}{ccc}\text { Table } 1 & \\ \text { Cell line } & C 3 H & F_{1}(C 3 H \times C B A) \\ \text { NCTC 2472 } & 19 / 19 * & 4 / 4 \\ \text { Hybrid 2472(28)/T-6 } & 14 / 18 & 6 / 6 \\ \text { Hybrid 2472(18)/T-6 } & 7 / 11 & - \\ T-6 & - & 0 / 5 \\ \text { * Animals with tumours/animals inoculated. }\end{array}$

It is clear that, in this case, the hybrids between cells of a 'permanent' neoplastic line and normal cells are both 'permanent' and neoplastic.

The decline of the percentage of hybrid cells observed at the usual culture temperature $\left(36^{\circ}-37^{\circ}\right)$ does not occur if the mixed cultures are incubated at $28^{\circ}-29^{\circ}$. At the lower temperature, the percentage of hybrid cells shows a rapid and continuous increase. Within a month after the beginning of an experiment, up to 99 per cent of the mitoses are of the hybrid type. 'The mechanism of this * Post-doctoral fellow of the U.S. Public Health Service.
+ On leave from the University of Paris.

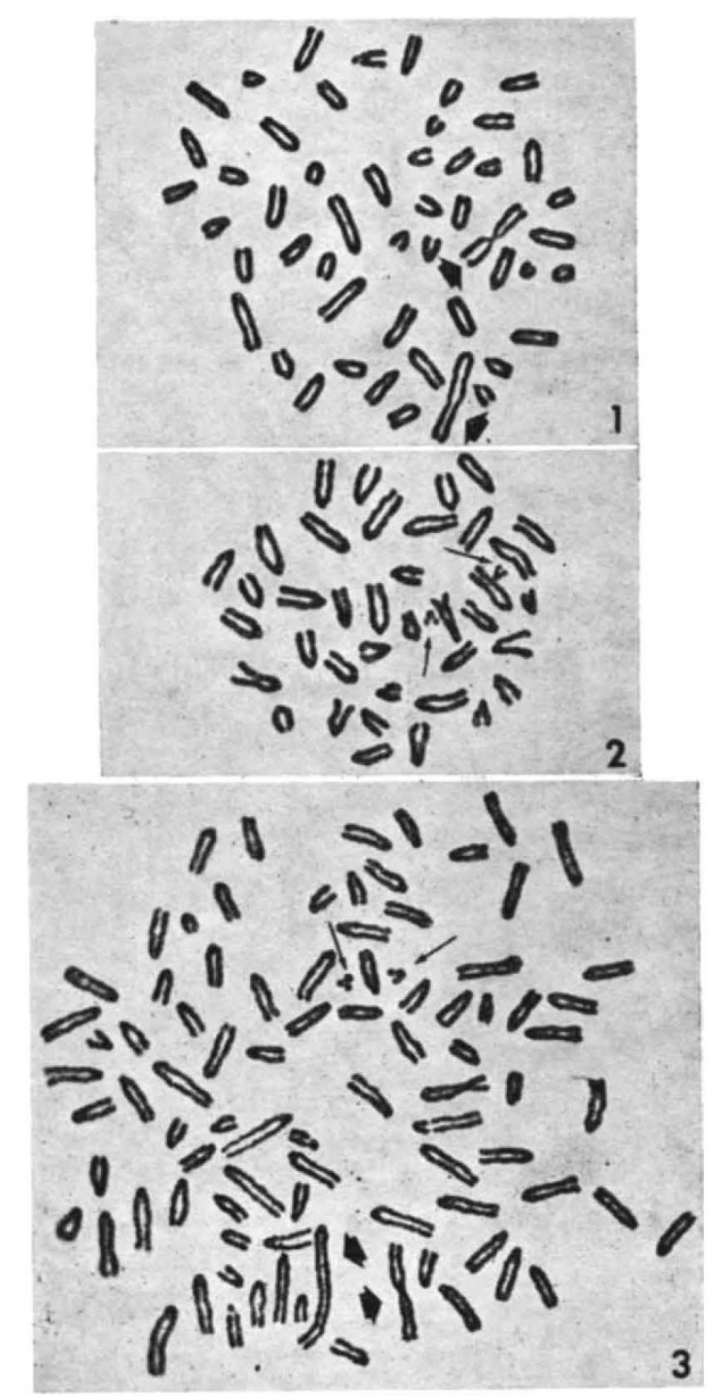

Fig. 1. Metaphase of a cell of line NCTC 2472 (clone No. 6). Note the presence of an extra long telocentric and of a bi-armed chromosome
(arrows)

Fig. 2. Metaphase of a diploid cell homozygous for the $T-6$ translocation
(arrows)

Fig. 3 Metaphase of a hybrid formed in a mixed culture of NCTC 2472 (clone No. 6 ) and $T-6$. The marker chromosomes areindicated by arrows

effect of low temperature is being investigated on several somatic cell hybrids. If the low-temperature effect proves to be characteristic of other hybrids as well, it could be used as a tool for the selection of hybrids between cells carrying no special selective markers.

This work was supported by a grant from the U.S. National Science Foundation $(R G-9916)$. 1 Ephrussi, B., Scaletta, L. J., Stenchever, M. A., and Yoshida, M. C., Symp.
Intern, Soc. Cell Biol., 3, 13 (1964).

"Sanford, K. K., Likely, G. D., and Earle, W. R., J. Nat. Cancer Inst., 15, 215 (1954).

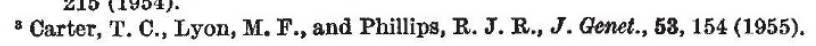

